\title{
A local, healthy, and sustainable food factory on wheels
}

Inge de Bresser

EUFIC - European Food Information Council

Food processing often conjures up images of big and far-remote factories. But can you imagine a small box much closer to the farm doing the same thing? The Horizon 2020 funded project FOX-Food processing in a bOX-aims to develop exactly that; integrating technologies for the mild processing of surplus fruits and vegetables into a mobile container that can move from farm to farm!

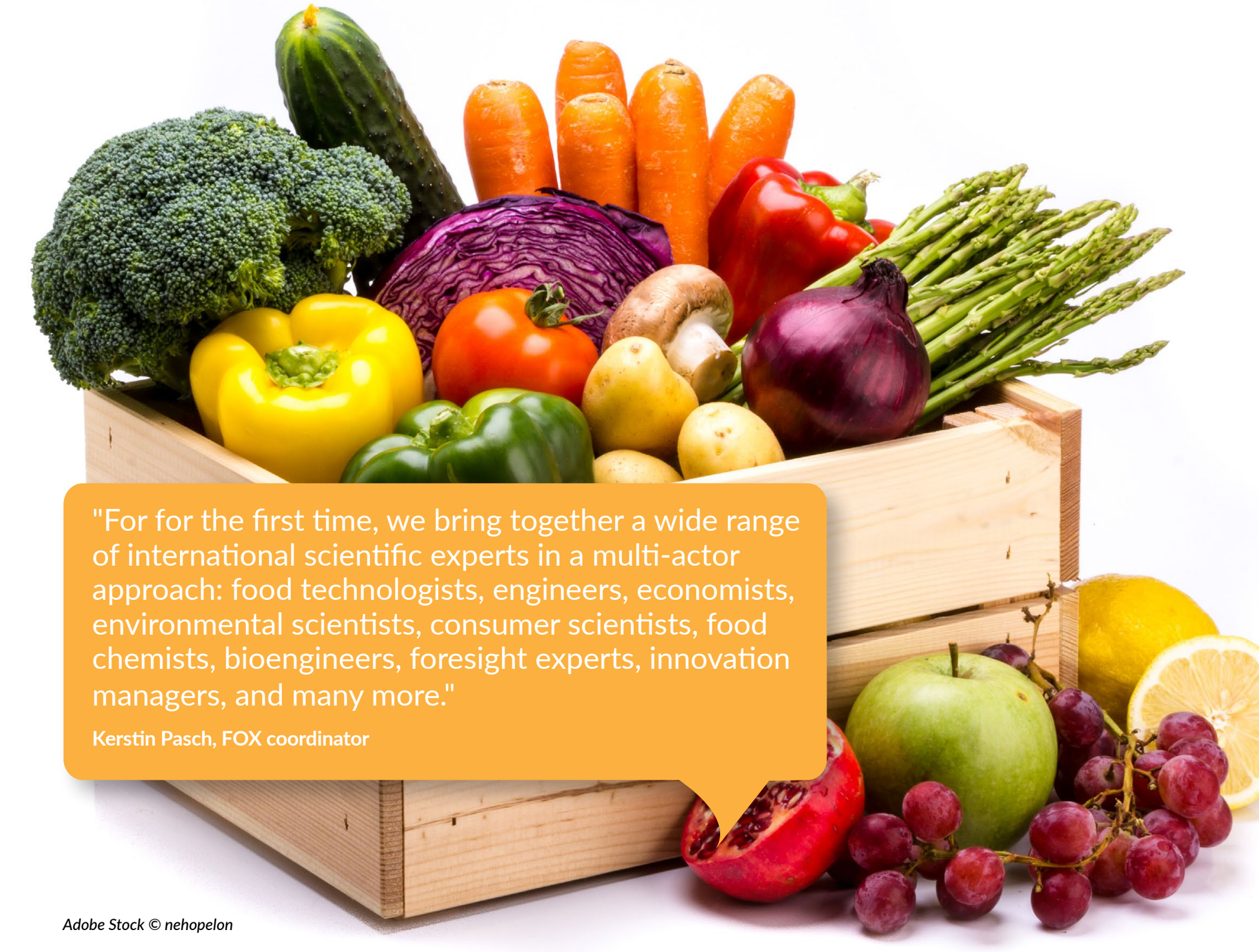

Local and healthy dried snacks in a mobile container

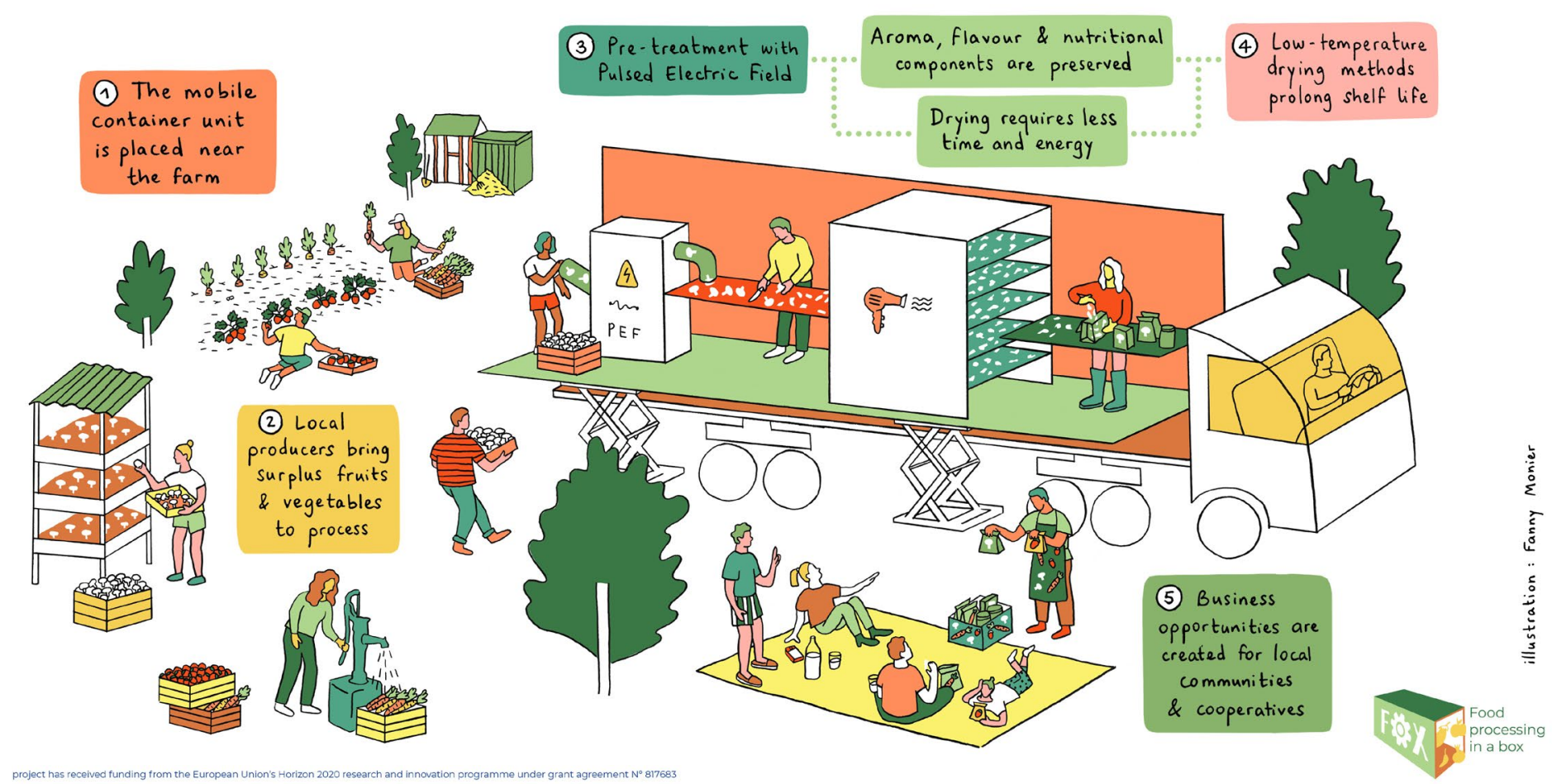

Figure 1: Infographic illustrating the FOX mobile container for the production of minimally processed dried fruit and vegetable snacks.

Striving for short-food

supply chains

With the FOX mobile container units the project works towards short food chains in which farmers can produce healthy and tasty products from their fruit or vegetable surpluses. In recent years, short food supply chains have become increasingly recognised as a sustainable alternative to the current centralised food system (Chiffoleau and Dourian, 2020) Short food supply chains are characterised by short distances or few intermedias betwen producers and consumes. With the FOX noble container units, a farmer can example, produce helthy unes for examp produce heathy juices from to consumers in the neighbourhood (Figure 1). This will create business opportunities for small scale farmers and reduce food waste and traffic to central factories. Besides, the short food supply chain is better resilient to global market descriptions in times of global crises (Belletti and Marescotti, 2020).
Figure 2: 3 D modes
vegetable juices.

What is in the container?

The mobile containers units will be equipped with technologies for the mild processing of fruits and vegetables (Figure 2). With health and sustainability as the project's core values, FOX researchers have investigated which technologies use the lowest amount of energy while preserving as much of the original nutrients as possible. 
Zero waste by upscaling fruit \& vegetable side streams

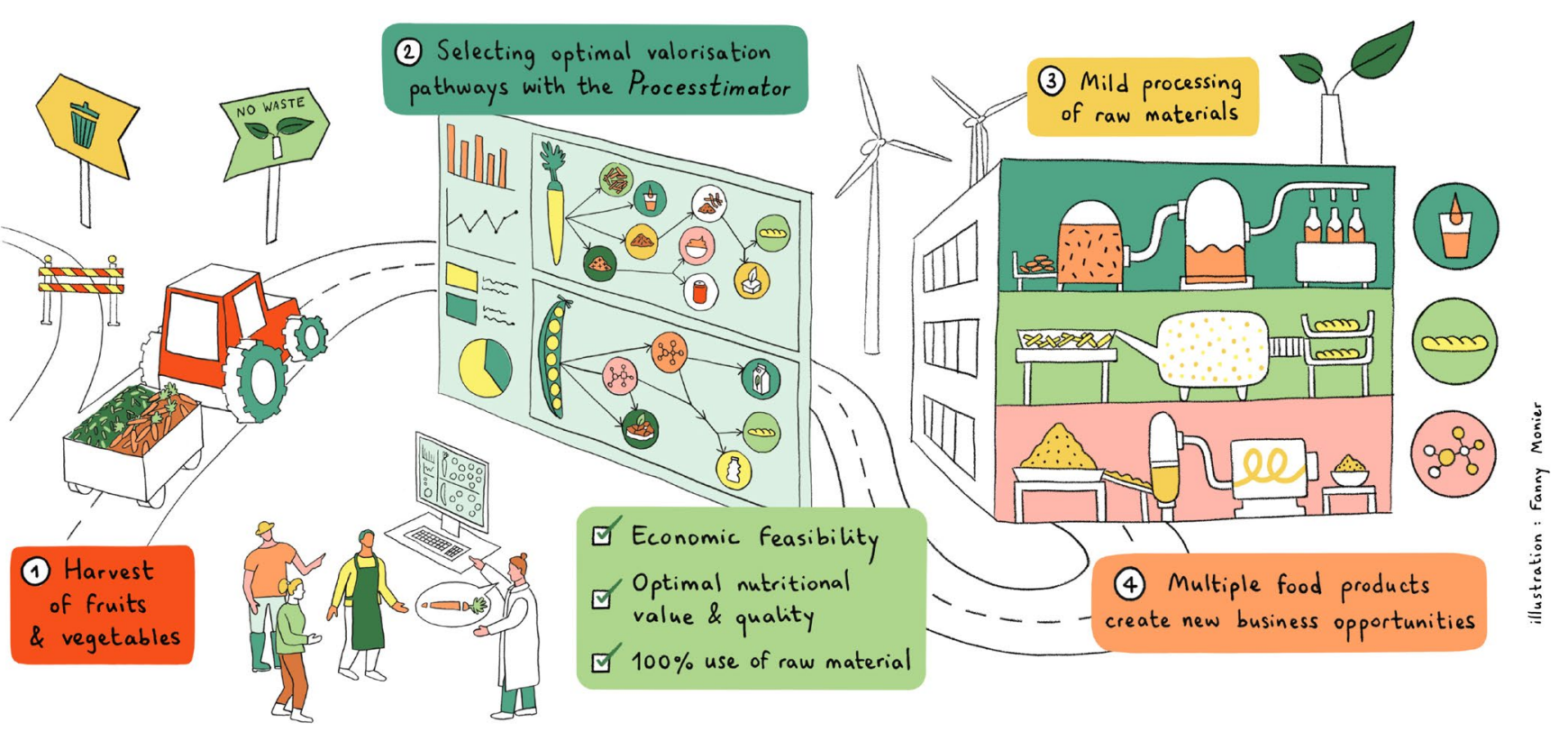

Figure 3: Infographic explaining how the FOX project reduces food waste by upscaling fruit and vegetable side streams.

Pulsed electric fields (PEF) is one of the promising mild processing technologies. In the project the technology will be used for two different applications: (1) the for two different applications: (1) the
preservation of fresh fruit $\&$ vegetable preservation of fresh fruit $\&$ vegetable
juices; and (2) the production of dried frut and vegetable snacks. In the FOX container that produces fruit and vegetable juices, PEF will create tiny holes in the cell membrane of bacteria in the freshly squeezed juice. This inactivates the juice (Figure 1). A major advantage the juice (Figure 1). A major advantage of the PEF technique is that it generates little heat, allowing the original nutritional components, taste, and aroma of products to be preserved. These advantages are further amplified by squeezing the juice with a vacuum spiral filter press that
minimises the contact between the juice and oxygen.

For the production of dried snacks in the other FOX container unit, PEF will be used to prepare the fruits and vegetables for drying. The pulsed electric field creates tiny holes in the cell membrane of the fruit vegetable while leaving the rest of the cell undamaged. The tiny holes enable water to escape easily and thereby facilitate the drying process that follows. At the current stage of the FOX project, researchers are investigating which drying method (hot air drying, microwave-assisted air drying, infrared drying or vacuum drying) can be value, taste, and aroma.

The first container prototype is under construction and will soon be equipped whe final contine small scale farmers across Europe.

\section{Zero waste}

But the FOX innovations even go beyond the development of mobile food processin units! The FOX project envisions short food supply chains in which zero food is wasted. That means every piece of a fruit or vegetable is used entirely, from tip to base. For example, when producing carrot
juice, the tip and base of a carrot are juice, the tip and base of a carrot are always cut off first. Instead of throwing these so-called side streams away, they can be used to produce other valuable ingredients or products, like fibres, soups, Trated carrots in the carrot example. the Processtimeter, which calculates how a specific side stream can best be used to ensure optimal value, food safety, shelf life and product quality. It considers the different mild processing techniques and their applications, such as PEF, highpressure processing, supercritical $\mathrm{CO}_{2}$ and extraction techniques. With this tool, farmers and other food producers can seek professional advice on valorising their side stream, avoiding food waste, and gaining optimal value for their harvest (Figure 3).

FOX also discovers how to reduce waste by sustainable packaging of end products. Researchers are investigating how FOX products can be sustainably packed. For exam can becylable tras made from For bas are being der as compostable package fresh-cut fruits and vustainably a mobile contait fruts and vegetables in Consumers come first

Of all the players within the food sector fam Food, 2020). With the mobile container units, the FOX project re-connects farmers and consumers by enabling consumers to buy products directly from a farmer in the neighbourhood. Not only will this lead to increased transparency and trust in the food chain, but consumers will also be empowered to eat locally and more sustainably. To ensure the final FOX innovations meet the consumers' expectations, the FOX consumer research

"The project makes sure end-users, like farmers, consumers or companies, and multipliers as associations, cooperatives or advisors are fully engaged during the whole project and contribute to it."

Kerstin Pasch, Head of DIL Brussels, FOX Coordinator

team makes sure that consumers are constantly involved. In the winter of 2022, the project will also launch its own app called FOXLINK. The app will serve as a communication channel and consumers, It will offer customised information on the local food production and technologies used in pach of the FOX regions.

Besides consumers, other end-users of the FOX innovations, the FOX innovations, such as farmers an in the project. From the beginning of the in the project. From the beginning of the
project, a community open to anyone project, a community open to anyone
interested in small scale food processing has been actively involved. Based on their expertise and experiences, the FOX innovations are tailored to the needs of farmers and small food businesses in of farmers and small food businesses it to get heard, interested people can easily to get heard, interested people can easily
subscribe to the community on the FOX subscribe to the con
website (FOX, 2021).

Compete in the

Compete in the food system of the future

"How can we increase the competitiveness of food products in short value chains? From my point of view, this is the biggest challenge," shared coordinator Kerstin Pasch at the start of the project. Indeed centralised food systems are trimmed to the highest efficiency, which poses challenges for short food supply chains to compete with lower volumes and different sales channels (Chiffoleau an Dourian, 2020; Mulligan and Berti, 2016). To ensure that the FOX innovations will compete in the current and future food system, an experienced team of scientists from different institutions are modellin the economic impact. In addition to developing strong business models, they have been identifying different scenarios for the European food system in 2035 , which enable the FOX innovations to be dapted to the food system of the future (Moller et al., 2019; Moller et al., 2020).

While a strong economic position is of major importance to make the project's innovations a success, the impact on health and sustainability are also key criteria in the FOX project. A vast keam of partners from all across Eust team curope are FOX in avations the impact of the environment.

Since the start of the project in June 2019, an international team of experts from a wide range of disciplines have been working hard to make the project a success. With just two years remaining, the image of healthy and sustainable food processing in a mobile container is increasingly becoming a reality.

References click here

\section{@ : healthy choices}

This article is part of the collaboration between EUFIC and embers of its Editorial board. EUFIC - The European Food Information Council, is a non-proft organisation, established in 1995. EUFIC's mission is to provide engaging science-based information and more sustainable food and lifestyle choices.

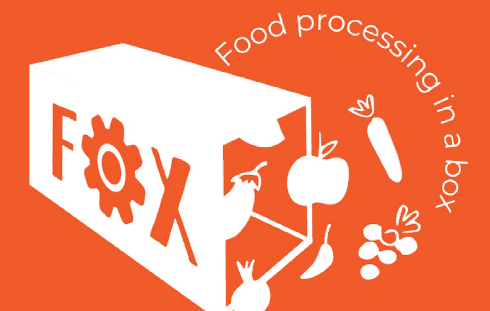

PROJECT SUMMARY

The FOX project stimulates short food supply chains for fruit and vegetables by developing innovative mild processing sochnologies and sustainable packaging units. The project enables small farmers to process their surpluses close to the farm and sustainably.

PROJECT LEAD

The FOX project coordinator, Dr Kerstin Pasch, is currently heading the Germ nn Institute of Food Technologies (DIL) Office in Brussels and the DIL Platform Network. DIL has a long tradition in food science and technology and considerable experience in European research projects.

PROJECT PARTNERS

The FOX consortium consists of multidisciplinary team of 25 partners from a wide variety of fields, including food technologists, engineers, economists, scientists, consumer, fortsts, food chemists, bioengineers, DIL, WUR, KUL, FRAUNHOFER, AU, AINIA, VUPP, SGGW, NUTRIS, EFFOST, ELEA, EUFIC, CTCPA, KOB, FOODTECH,
FALENSTEIN KPGROUP, TERRA, FALKENSTEIN, KPGROUP, TERRA,
OCHSEN, AGRO CR, CEDRUS, SMA CZ, SATU, RIJINGEN, and HUTTEN.

CONTACT DETAILS

Dr Kerstin Pasch

DIL, Project Coordinator

info@fox-foodprocessinginabox.eu

fox-foodprocessinginabox.eu

EU Food Health

in FOX - Food Processing in a Box

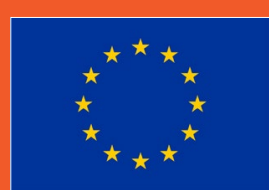

FUNDING

FOX has received funding from the European
Union's Horizon 2020 research and innovation Union's Horizon 2020 research and innovation 


\section{A local, healthy, and sustainable food factory on wheels}

\section{References}

Belletti, G., Marescotti, A. (2020) Short food supply chains for promoting local food on local markets: inclusive and sustainable industrial development, United Nations Industrial Development Organization. Available at: tii.unido.org/news/strengthening-resilience-food-systems-role-short-food-supply-chains.

Berti, G. and Mulligan, C. (2016) 'Competitiveness of small farms and innovative food supply chains: The role of food hubs in creating sustainable regional and local food systems', Sustainability, 8(7), p.616. doi: 10.3390/su8070616.

Chiffoleau, Y. and Dourian, T. (2020) 'Sustainable food supply chains: is shortening the answer? A literature review for a research and innovation agenda', Sustainability, 12(23), p.9831. doi: 10.3390/su12239831.

EIT Food (2020) The EIT Food Trust Report, EIT food. Available at: www.eitfood.eu/media/news-pdf/EIT_Food_Trust_Report_2020.pdf.

FOX - Food processing in a box (2021) FOX Small Scale Food Processors Interest Group. Available at: www.fox-foodprocessinginabox.eu/european-interestgroup/ (Accessed: 25 July 2021).

Moller, B.P., Voglhuber-Slavinsky, A., Dönitz, E. and Rosa, A. (2019) 50 trends influencing Europe's food sector by 2035, Fraunhofer Institute for Systems and Innovations Research ISI. Available at: https://www.isi.fraunhofer.de/content/dam/isi/dokumente/ccv/2019/50-trends-influencing-Europes-food-sector.pdf. 